\title{
Alterações químicas de Argissolo irrigado com percolado de aterro sanitário e água de abastecimento
}

\author{
Daniela da C. L. Coelho ${ }^{1}$, Rafael O. Batista ${ }^{1}$, Adriana de F. M. Oliveira ${ }^{2} \&$ Ketson B. da Silva $^{1}$ \\ ${ }^{1}$ Departamento de Ciências Ambientais e Tecnológicas/Universidade Federal Rural do Semi-Árido. Mossoró, RN. E-mail: danielacleite@yahoo.com.br; \\ rafaelbatista@ufersa.edu.br (Autor correspondente); ketsonbruno@hotmail.com \\ ${ }^{2}$ Departamento de Ciências Vegetais/Universidade Federal Rural do Semi-Árido. Mossoró, RN. E-mail: oliveira.adrianamendes@gmail.com
}

\section{Palavras-chave:}

resíduo líquido urbano

impactos no solo

reúso

\begin{abstract}
R E S U M O
Este trabalho objetivou analisar os efeitos da aplicação de dosagens de percolado de aterro sanitário (PATS) + água de abastecimento (AA) na alteração química de argissolo cultivado com capim elefante. O experimento foi montado em esquema de parcelas subsubdivididas, no delineamento em blocos casualizados com cinco repetições tendo, nas parcelas, as dosagens de PATS + AA (T1 - 0 mm de PATS + AA; T2 - 1 mm de PATS + AA; T3 - 2 mm de PATS + AA; T4 - 3 mm de PATS + AA; e T5 - 4 mm de PATS + AA), nas subparcelas as profundidades analisadas ( 0 a $0,2 \mathrm{~m}$ e 0,2 a $0,4 \mathrm{~m})$ e nas subsubparcelas os tempos de amostragem $(0,30$, 60,90 e 120 dias). Amostras de solo foram realizadas a cada 30 dias, durante 120 dias para determinação de características químicas. As características químicas analisadas variaram apenas com relação às profundidades, em que a condutividade elétrica do extrato de saturação do solo, a matéria orgânica, o nitrogênio, o potássio, a soma de bases e a capacidade de troca catiônica diminuíram ao longo do perfil do solo enquanto o cálcio aumentou e o magnésio se manteve constante. $\mathrm{O}$ tratamento correspondente a $1 \mathrm{~mm}$ de PAST + AA foi o mais recomendado para aplicação em Argissolo cultivado com capim elefante.
\end{abstract}

\section{Key words:}

urban liquid waste soil impacts

reuse

\section{Chemical changes in Argisol irrigated with landfill leachate and water supply}

\begin{abstract}
A B S T R A C T
This study aimed to analyse the effect of different dosages of landfill leachate (PATS) plus water supply (AA) on chemical alteration of Ultisol cultivated with Pennisetum purpureum. The experiment was set up in split-split plot scheme in randomized blocks with five replications, where PATS plus AA dosages (T1 - $0 \mathrm{~mm}$ PATS + AA, T2 - $1 \mathrm{~mm}$ PATS + AA, T3 - 2 mm PATS + AA, T4 - 3 mm PATS + AA, and T5 - 4 mm PATS + AA) in plot, analysed depths (0 to $0.2 \mathrm{~m}$ and 0.2 to $0.4 \mathrm{~m})$ in splitplots and the sampling times $(0,30,60,90$ and 120 days) on splitsplitplots. Soil samples were collected every 30 days up to 120 days for chemical characterization. The analysed chemical characteristics varied only with depth, where electrical conductivity of the soil saturation extract, organic matter, nitrogen, potassium, sum of bases and cation exchange capacity decreased over the soil profile while calcium increased and magnesium remained constant. The corresponding treatment to $1 \mathrm{~mm}$ of PATS + AA is the most recommended for use in Argisol cultivated with elephant grass.
\end{abstract}




\section{INTRODUÇÃo}

A disposição dos resíduos sólidos urbanos em aterros sanitários é uma prática adotada no território brasileiro em função dos custos reduzidos e da disponibilidade de áreas para sua implantação (França \& Ruaro, 2009; Castilhos Júnior et al., 2010).

Porém, aterro sanitário requer preocupações cotidianas no que se refere às medidas de proteção do ambiente local e próximo (Moreira \& Braga, 2009), tendo em vista o impacto dos vetores da poluição dessa instalação de disposição final (Corrêa et al., 2011), os gases (Silva \& Campos, 2008) e os importantes volumes de lixiviados gerados (Queiroz et al., 2011).

O tratamento de percolados oriundos do processo de degradação anaeróbia de resíduos sólidos urbanos dispostos no solo de forma desordenada ou em aterros sanitários é, atualmente, um dos problemas enfrentados pela área do saneamento (Dacanal \& Beal, 2010).

Mesmo aterrados, os resíduos sólidos urbanos geram um líquido de coloração escura, altamente poluidor, denominado percolado, resultante da degradação e solubilização do material orgânico dos resíduos sólidos urbanos, com a água infiltrada no aterro (Matos et al., 2008; Bortolin \& Malagutti Filho, 2010).

As fontes hídricas de percolação podem ser a irrigação, precipitação pluviométrica, águas subterrâneas ou percoladas recirculadas através da célula do aterro sanitário (Martins et al., 2010; Oliveira et al., 2011).

O percolado proveniente de aterros sanitários apresenta alta variabilidade composicional, destacando-se a presença de nutrientes importantes para a agricultura, como o nitrogênio, fósforo, potássio e alguns micronutrientes, além de matéria orgânica (Matos et al., 2013), atribuindo-lhe elevado potencial para aproveitamento agrícola.

No que se refere à irrigação de culturas agrícolas (Matos et al., 2008) entretanto, o sódio e outros poluentes podem ser fatores limitantes para este aproveitamento (Silva et al., 2010).

Com base no exposto objetivou-se analisar o efeito da aplicação de distintas dosagens de percolado de aterro sanitário na alteração química de um argissolo cultivado com capim elefante (Pennisetum purpureum Schum.).

\section{Material e Métodos}

O trabalho foi realizado na Unidade Experimental de Reúso de Água (UERA) da Universidade Federal Rural do Semiárido (UFERSA) em Mossoró, RN, sob as coordenadas geográficas $5^{\circ} 11^{\prime} 31^{\prime \prime}$ de latitude sul e $37^{\circ} 20^{\prime}$ ' $40^{\prime \prime}$ de longitude oeste.

O clima da região, segundo a classificação de Köppen, é do tipo BSwh' ("clima seco, muito quente e com estação chuvosa no verão atrasando-se para o outono"), com precipitação pluviométrica bastante irregular e média anual de $673,9 \mathrm{~mm}$; temperatura média de $27^{\circ} \mathrm{C}$ e umidade relativa do ar média de 68,9 \% (Carmo Filho \& Oliveira, 1995).

O solo da área experimental foi classificado como Argissolo Vermelho-amarelo eutrófico (EMBRAPA, 2013), tendo camada impermeável a partir da profundidade de 0,4 m. Apresentamse, nas Tabelas 1 e 2, as características químicas e físicas do solo da área experimental, antes da aplicação do percolado de aterro sanitário determinadas pela metodologia proposta por Donagema et al. (2011).

As atividades foram desenvolvidas no período de abril a agosto de 2012; para isto, transportou-se o percolado do aterro sanitário do município para a UERA/UFERSA em recipiente plástico com capacidade armazenadora para $1000 \mathrm{~L}$. Enquanto a água de abastecimento utilizada no trabalho foi oriunda da rede pública da Companhia de Águas e Esgotos do Rio Grande do Norte (CAERN).

As características físico-químicas e microbiológicas do percolado de aterro sanitário e da água da rede de abastecimento foram determinadas mensalmente, no período de maio a agosto de 2012, seguindo as recomendações do Standard Methods for the Examination of Water and Wastewater (Rice et., 2012), conforme apresentado na Tabela 3.

As aplicações do percolado de aterro sanitário foram realizadas a cada dois dias, antes da irrigação com água de abastecimento, de forma a favorecer a lixiviação dos elementos químicos, ao longo do perfil do solo. Durante a aplicação do percolado de aterro sanitário adotaram-se os seguintes procedimentos: a) mistura do percolado, para homogeneização, evitando-se que sedimentos ficassem retidos no fundo do recipiente; b) medição da quantidade específica dentro de

Tabela 1. Características químicas do solo antes da aplicação do percolado de aterro sanitário

\begin{tabular}{|c|c|c|c|c|c|c|c|c|}
\hline \multirow{2}{*}{$\begin{array}{l}\text { Profundidade } \\
\text { (m) }\end{array}$} & \multirow{2}{*}{ pH } & \multirow{2}{*}{$\begin{array}{c}\text { CEes } \\
\left(\mathrm{dS} \mathrm{m}^{-1}\right)\end{array}$} & \multirow{2}{*}{$\begin{array}{c}\text { MO } \\
\text { (dag kg-1) }\end{array}$} & \multirow{2}{*}{$\begin{array}{c}N \\
\left(g^{k g} g^{-1}\right)\end{array}$} & $\mathbf{K}^{+}$ & $\mathrm{Na}^{+}$ & $\mathrm{Ca}^{2+}$ & $\mathrm{Mg}^{2+}$ \\
\hline & & & & & \multicolumn{2}{|c|}{$\left(\mathrm{mg} \mathrm{dm}^{-3}\right) \mathrm{Na}^{+}$} & \multicolumn{2}{|c|}{$\left(\mathrm{cmol}_{\mathrm{c}} \mathrm{dm}^{-3}\right)$} \\
\hline $0-0,20$ & 6,6 & 0,12 & 0,68 & 0,54 & 104,45 & 13,64 & 2,09 & 0,79 \\
\hline $0,20-0,40$ & 6,6 & 0,13 & 0,57 & 0,62 & 121,88 & 9,28 & 2,46 & 1,17 \\
\hline
\end{tabular}

CEes - Condutividade elétrica do extrato de saturação do solo; e MO - Matéria orgânica.

Tabela 2. Características físicas do solo antes da aplicação do percolado de aterro sanitário

\begin{tabular}{|c|c|c|c|c|c|c|}
\hline \multirow{2}{*}{$\begin{array}{l}\text { Profundidade } \\
\text { (m) }\end{array}$} & \multirow{2}{*}{$\begin{array}{c}\text { Densidade do solo } \\
\mathrm{g} \mathrm{cm}^{-3}\end{array}$} & Areia & \multirow{2}{*}{$\frac{\text { Silte }}{\mathrm{kg} \mathrm{kg}^{-1}}$} & \multirow[t]{2}{*}{ Argila } & \multicolumn{2}{|c|}{ Umidade (\%) } \\
\hline & & & & & $0,01 \mathrm{MPa}$ & $1,5 \mathrm{MPa}$ \\
\hline $0-0,20$ & 1,61 & 0,85 & 0,1 & 0,05 & 11,43 & 3,67 \\
\hline $0,20-0,40$ & 1,65 & 0,70 & 0,07 & 0,23 & 21,47 & 14,17 \\
\hline
\end{tabular}

Tabela 3. Valores médios e desvios padrão de quatro amostragens, das características químicas do percolado de aterro sanitário (PATS) e da água de abastecimento (AA) no período de maio a gosto de 2012

\begin{tabular}{|c|c|c|c|c|c|c|c|}
\hline \multirow{2}{*}{ Fluídos } & \multirow{2}{*}{$\mathrm{pH}$} & \multirow{2}{*}{$\begin{array}{c}C E \\
\left(\mathrm{dS} \mathrm{m}^{-1}\right)\end{array}$} & $N_{\text {total }}$ & $\mathrm{N}-\mathrm{NO}_{3}{ }^{-}$ & $\mathbf{K}^{+}$ & $\mathrm{Ca}^{2+}$ & $\mathrm{Mg}^{2+}$ \\
\hline & & & \multicolumn{2}{|c|}{$\left(\mathrm{mg} \mathrm{L}^{-1}\right)$} & \multicolumn{3}{|c|}{$\left(\mathrm{mmol}_{\mathrm{c}} \mathrm{L}^{-1}\right)$} \\
\hline PATS & $7,45 \pm 0,45$ & $16,40 \pm 1,68$ & $592,00 \pm 51,81$ & $10,13 \pm 5,02$ & $58,55 \pm 13,85$ & $10,44 \pm 3,15$ & $18,38 \pm 8,73$ \\
\hline $\mathrm{AA}$ & $7,47 \pm 0,36$ & $0,76 \pm 0,30$ & $0 \pm 0$ & $0 \pm 0$ & $0,39 \pm 0,06$ & $2,98 \pm 1,76$ & $2,86 \pm 0,62$ \\
\hline
\end{tabular}

AA - Água da rede de abastecimento; PATS - Percolado de aterro sanitário; $\mathrm{pH}$ - Potencial hidrogeniônico; CE - Condutividade elétrica; $\mathrm{N}_{\text {total }}$ - Nitrogênio total; $\mathrm{N}$-NO ${ }_{3}^{-}$- Nitrato na forma de nitrogênio; $\mathrm{K}^{+}$- Potássio; $\mathrm{Na}^{+}$- Sódio; $\mathrm{Ca}^{2+}$ - Cálcio; $\mathrm{Mg}^{2+}$ - Magnésio 
um balde graduado; c) transferência da quantidade medida para um regador de 5,0 L e d) Aplicação do percolado com auxílio do regador, diretamente no solo, dentro de cada parcela experimental.

Para a aplicação da água de abastecimento foi montada uma bancada experimental constituída dos seguintes componentes: a) um reservatório de concreto com capacidade de armazenamento para $16 \mathrm{~m}^{3}$; b) um conjunto motobomba centrífugo com potência de $0,25 \mathrm{cv}$ : c) um filtro de disco com aberturas de $130 \mu \mathrm{m}$; d) uma linha principal de tubo de PVC com $24 \mathrm{~m}$ de comprimento e $32 \mathrm{~mm}$ de diâmetro nominal e) uma linha de derivação de tubo de PVC com $12 \mathrm{~m}$ de comprimento e $50 \mathrm{~mm}$ de diâmetro nominal e f) 24 linhas laterais com espaçamento de $0,50 \mathrm{~m}$, dotadas de emissores nãoautocompensantes de 1,6 $\mathrm{L} \mathrm{h}^{-1}$ de vazão nominal e espaçamento entre emissores de $0,30 \mathrm{~m}$.

O conjunto de irrigação por gotejamento ocupou uma área de $38,44 \mathrm{~m}^{2}$, na qual foram delimitadas 25 parcelas experimentais.

Cada parcela experimental foi construída nas dimensões de $1,0 \times 1,0 \mathrm{~m}$ (1,0 $\mathrm{m}^{2}$ cada), e 0,30 m entre parcelas, sendo cultivado o capim elefante (Pennisetum purpureum Schum.). O plantio do capim elefante foi realizado no dia 21 de abril de 2012, tendo-se colocado, em cada parcela, nove colmos.

As cinco parcelas submetidas ao tratamento $\mathrm{T}_{1}$ (somente água da rede de abastecimento) não receberam adubação alguma de fundação enquanto as demais parcelas receberam apenas o aporte de nutrientes presentes no percolado de aterro sanitário no decorrer do período experimental.

A determinação da necessidade hídrica do capim elefante foi estimada com base no balanço de água no solo e na evapotranspiração de referência empregando-se a metodologia da FAO por meio da equação de Penman-Monteith (Allen et al., 2006).

Os dados meteorológicos necessários para a estimativa da evapotranspiração de referência (ETo) pela equação de Penman-Monteith como velocidade do vento, umidade relativa do ar, insolação, radiação solar e temperatura, foram obtidos de uma estação meteorológica instalada na UFERSA, câmpus Mossoró-RN. Para estimar a evapotranspiração da cultura (ETc) utilizaram-se os valores de coeficiente de cultura (Kc) de 0,85 , definidos pela FAO para o estágio de desenvolvimento II, citado por Lopes et al. (2003).

Os tratamentos utilizados foram: a) $\mathrm{T}_{1}$ - Somente água de abastecimento pela demanda hídrica da cultura; b) $\mathrm{T}_{2}-1 \mathrm{~mm}$ de percolado de aterro sanitário + água de abastecimento pela demanda hídrica da cultura; c) $\mathrm{T}_{3}-2 \mathrm{~mm}$ de percolado de aterro sanitário + água de abastecimento pela demanda hídrica da cultura; $\mathrm{T}_{4}$ - $3 \mathrm{~mm}$ de percolado de aterro sanitário + água de abastecimento pela demanda hídrica da cultura e $\mathrm{T}_{5}-4$ $\mathrm{mm}$ de percolado de aterro sanitário + água de abastecimento pela demanda hídrica da cultura. As lâminas dos tratamentos utilizadas nos ensaios experimentais estão apresentadas na Tabela 4.

Para avaliação das alterações nas características químicas do solo foram coletadas amostras, a cada 30 dias, durante 120 dias, nas profundidades de 0 a $0,2 \mathrm{~m} \mathrm{e} 0,2$ a $0,4 \mathrm{~m}$. Coletaramse as amostras com auxílio de trato holandês em cada uma das 25 parcelas experimentais, sendo duas amostras simples
Tabela 4. Lâminas dos tratamentos com dosagens de percolado de aterro sanitário (PATS) + água de abastecimento (AA), utilizadas nos ensaios experimentais

\begin{tabular}{cccc}
\hline \multirow{2}{*}{ Tratamentos } & \multicolumn{3}{c}{ Lâminas (mm) } \\
\cline { 2 - 4 } $\mathrm{T}_{1}$ & PATS & AA & PATS + AA \\
$\mathrm{T}_{2}$ & 0 & 1066,56 & 1066,56 \\
$\mathrm{~T}_{3}$ & 60 & 1066,56 & 1126,56 \\
$\mathrm{~T}_{4}$ & 120 & 1066,56 & 1186,56 \\
$\mathrm{~T}_{5}$ & 180 & 1066,56 & 1246,56 \\
\hline
\end{tabular}

para formar uma amostra composta, em cada profundidade e para cada parcela, sempre próximo aos gotejadores e ao capim elefante; em seguida, as amostras foram armazenadas em sacos plásticos estéreis etiquetados e encaminhadas ao Laboratório de Análise de Solo, Água e Planta (LASAP) da UFERSA onde foram quantificados os valores de matéria orgânica (MO) determinados pelo método Walkley-Black, nitrogênio $(\mathrm{N})$, condutividade elétrica do extrato de saturação do solo (CEes), potássio $(\mathrm{K})$ extraídos com Mehlich 1 , cálcio $(\mathrm{Ca})$ extraído com $\mathrm{KCl} 1 \mathrm{~mol} \mathrm{~L}^{-1}$, magnésio $(\mathrm{Mg})$ extraído com $\mathrm{KCl} 1 \mathrm{~mol}$ $\mathrm{L}^{-1}$, soma de bases (SB) e capacidade de troca catiônica (CTC) seguindo as metodologias da Donagema et al. (2011).

$\mathrm{O}$ experimento foi montado em esquema de parcelas subsubdivididas no delineamento em blocos casualizados (DBC) com cinco repetições, tendo nas parcelas as dosagens de percolado de aterro sanitário mais água de abastecimento (T1, T2, T3, T4 e T5), nas subparcelas as profundidades analisadas ( 0 a $0,2 \mathrm{~m}$ e 0,2 a $0,4 \mathrm{~m}$ ) e nas subsubparcelas os tempos de amostragem (0, 30, 60, 90 e 120 dias) com base na metodologia proposta por Silva et al. (2010).

Os dados de solo coletados foram submetidos à análise de variância empregando-se Teste $\mathrm{F}$ a 0,05 de probabilidade. Nas análises estatísticas utilizou-se o programa computacional Sisvar 5.1 Build 72 (Ferreira, 2011).

\section{Resultados e Discussão}

$\mathrm{Na}$ Tabela 5 está apresentado o resumo da análise de variância (ANOVA) das variáveis matéria orgânica (MO), nitrogênio $(\mathrm{N})$, condutividade elétrica do extrato de saturação do solo (CEes), potássio $\left(\mathrm{K}^{+}\right)$, cálcio $\left(\mathrm{Ca}^{+2}\right)$, magnésio $\left(\mathrm{Mg}^{+2}\right)$, soma de bases (SB) e capacidade de troca catiônica (CTC), no esquema de parcelas subsubdivididas.

Evidenciou-se, nessa tabela, que houve diferença estatística para a interação TA $x \mathrm{P} \times \mathrm{T}$ em referência à variável $\mathrm{K}^{+}$, enquanto as demais variáveis não apresentaram diferença estatística para esta interação. Os valores de CV subsubparcelas oscilaram de 27 a $68 \%$ inferiores à faixa de 4 a $60 \%$ obtida por Santos et al. (2009) para atributos químicos de Latossolo Amarelo.

Verificou-se que os valores de MO reduziram ao longo do perfil do solo, para todos os tratamentos aplicados (Figura 1A). Os maiores valores de MO ocorreram na camada mais superficial do solo porém houve um comportamento distinto dos tratamentos aplicados. O tratamento T4 foi o que apresentou menor variação nos teores de $\mathrm{MO}$, ao longo do perfil do solo; já com relação aos demais tratamentos (T1, T2, T3, e T5), evidenciou-se que quanto maior a dosagem de percolado de aterro sanitário, menor foi o aporte de MO. Smanhotto et 
Tabela 5. Análise de variância das variáveis matéria orgânica $(\mathrm{MO})$, nitrogênio $(\mathrm{N})$, condutividade elétrica do extrato de saturação do solo $(\mathrm{CEes})$, potássio $\left(\mathrm{K}^{+}\right)$, cálcio $\left(\mathrm{Ca}^{+2}\right)$, magnésio $\left(\mathrm{Mg}^{+2}\right)$, soma de bases $(\mathrm{SB})$ e capacidade de troca catiônica (CTC), no esquema de parcelas subsubdivididas

\begin{tabular}{|c|c|c|c|c|c|c|c|c|c|}
\hline \multirow{2}{*}{$\begin{array}{c}\text { Fontes } \\
\text { de variacãa }\end{array}$} & \multirow{2}{*}{$\begin{array}{c}\text { Graus } \\
\text { de liberdade }\end{array}$} & \multicolumn{8}{|c|}{ Quadrado médio } \\
\hline & & MO & $\mathbf{N}$ & CEes & $\mathbf{K}^{+}$ & $\mathrm{Ca}^{2+}$ & $\mathrm{Mg}^{2+}$ & SB & CTC \\
\hline Blocos & 4 & 0,61 & 0,02 & 0,55 & 85792 & 5,95 & 3,44 & 23,33 & 31,79 \\
\hline Tratamento (T) & 4 & $0,31^{\mathrm{ns}}$ & $0,02^{\text {ns }}$ & $2,66^{\star \star}$ & $853405^{\star \star}$ & $3,23^{* *}$ & $0,57^{\mathrm{ns}}$ & $15,87^{\star}$ & $15,46^{\star}$ \\
\hline Resíduos (a) & 16 & 0,15 & 0,02 & 0,38 & 48800 & 0,64 & 0,66 & 4,07 & 4,60 \\
\hline Profundidade $(\mathrm{P})$ & 1 & $4,89^{\star *}$ & $0,24^{* *}$ & $12,57^{\star *}$ & $2630200^{\star *}$ & $3,85^{\star \star}$ & $1,29^{\text {ns }}$ & $89,47^{* *}$ & $72,22^{* *}$ \\
\hline $\mathrm{P} \times \mathrm{T}$ & 4 & $0,15^{\text {ns }}$ & $0,003^{\text {ns }}$ & $0,47^{\text {ns }}$ & $169425^{\star}$ & $0,20^{\mathrm{ns}}$ & $1,48^{\star}$ & $10,86^{\star}$ & $11,10^{*}$ \\
\hline Resíduo (b) & 16 & 0,09 & 0,008 & 0,28 & 46727 & 0,39 & 0,42 & 3,16 & 3,22 \\
\hline Tempo de amostragem (TA) & 4 & $7,07^{\star \star}$ & $2,05^{\star *}$ & $5,17^{\star \star}$ & $1299963^{* \star}$ & $7,62^{\star \star}$ & $90,28^{\star *}$ & $341,60^{\star *}$ & $334,48^{\star *}$ \\
\hline $\mathrm{TA} \times \mathrm{T}$ & 16 & $0,14^{\mathrm{ns}}$ & $0,03^{* *}$ & $0,37^{\star \star}$ & $107282^{\star *}$ & $0,32^{\text {ns }}$ & $0,18^{\text {ns }}$ & $6,37^{\star}$ & $5,94^{\star}$ \\
\hline TA $\times P$ & 4 & $0,17^{\mathrm{ns}}$ & $0,08^{\star \star}$ & $1,68^{\star \star}$ & $422263^{\star *}$ & $0,77^{\text {ns }}$ & $2,26^{\mathrm{ns}}$ & $27,31^{\star \star}$ & $24,07^{\star \star}$ \\
\hline$T A \times P \times T$ & 16 & $0,06^{\mathrm{ns}}$ & $0,02^{\text {ns }}$ & $0,19^{\text {ns }}$ & $63710^{* *}$ & $0,34^{\mathrm{ns}}$ & $0,26^{\text {ns }}$ & $4,48^{\text {ns }}$ & $4,68^{\text {ns }}$ \\
\hline Resíduo (c) & 164 & 0,11 & 0,01 & 0,16 & 26580 & 0,47 & 1,10 & 3,44 & 3,47 \\
\hline CV parcela (\%) & & 40 & 53 & 104 & 66 & 37 & 39 & 30 & 31 \\
\hline CV subparcela (\%) & & 30 & 31 & 89 & 65 & 29 & 31 & 26 & 26 \\
\hline CV subsubparcela (\%) & & 34 & 39 & 68 & 49 & 31 & 50 & 27 & 27 \\
\hline
\end{tabular}

$*{ }^{* *}{ }^{*} \mathrm{e}^{\text {ns }}, \mathrm{F}$ significativo a 0,01 e 0,05 de probabilidade e não significativo a 0,05 de probabilidade
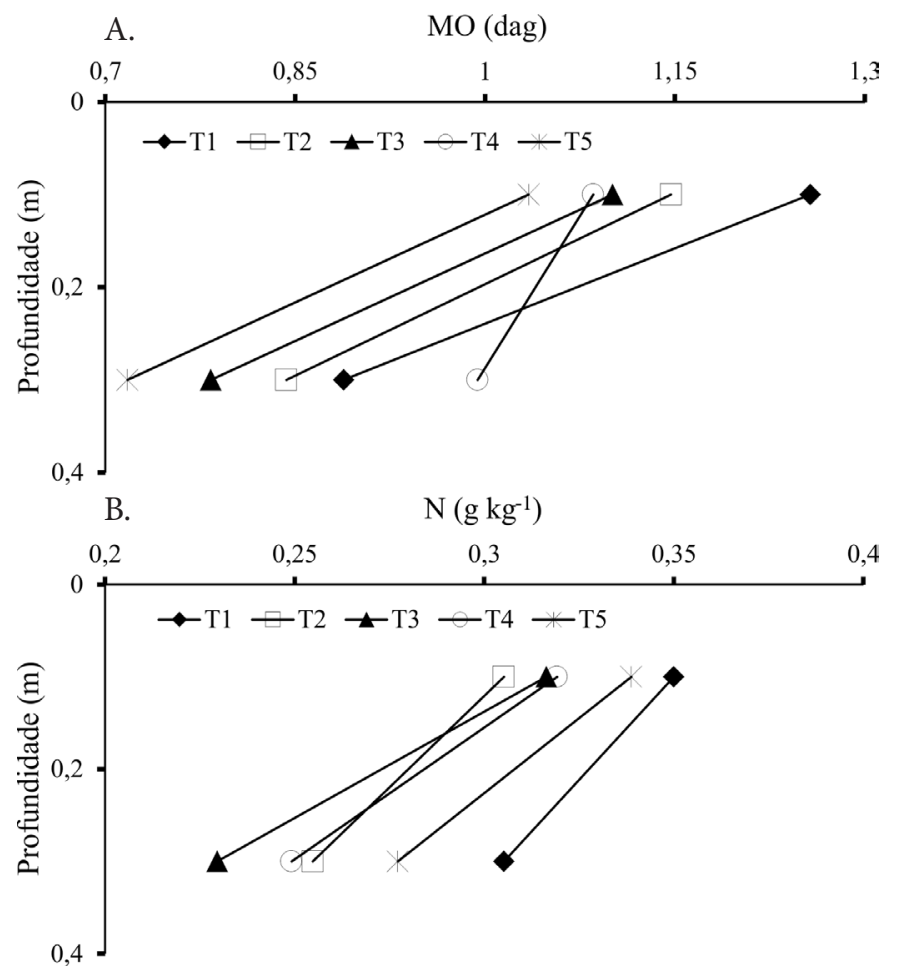

Figura 1. Alterações dos teores de matéria orgânica - MO $\left(\right.$ dag $\left.\mathrm{kg}^{-1}\right)$ e $\mathrm{N}\left(\mathrm{g} \mathrm{kg}^{-1}\right)$ em função da profundidade do solo e das doses de percolado de aterro sanitário + água de abastecimento conforme Tabela 4

al. (2010) trabalharam em condições experimentais diferentes com água residuária de suinocultura e notaram que o teor de $\mathrm{MO}$ variou em função das taxas de aplicação e em função da quantidade de $\mathrm{MO}$ presente no efluente.

Em trabalho desenvolvido por Medeiros et al. (2005), também se constatou que houve redução de MO no solo comparando-o com os tratamento sob aplicação de água residuária doméstica e manejo convencional. De acordo com a CFSEMG (1999), a classificação de interpretação de fertilidade do solo para o aporte de matéria orgânica, nas profundidades de 0,0 a 0,20 e 0,20 a $0,40 \mathrm{~m}$, é caracterizada como baixa $(0,71$ a 2,00 dag $\left.\mathrm{kg}^{-1}\right)$ para as duas profundidades estudadas.

Observou-se, na Figura 1B, que os valores de $\mathrm{N}$ diminuíram ao longo do perfil do solo, para todos os tratamentos aplicados.
Este fato pode ser explicado pela menor mineralização da MO na camada de 0,0 a 0,20 m. O tratamento T3 foi o que apresentou maior variação nas concentrações de $\mathrm{N}$, ao longo do perfil do solo; já com relação aos tratamentos T1 e T5, notou-se que a maior dose de percolado de aterro sanitário (T5) apresentou comportamento semelhante ao tratamento T1.

As observações acima podem ser explicadas devido ao fato de que a maior parte do nitrogênio presente em águas residuárias se encontra na forma orgânica, podendo ser mineralizada após disposição no solo, por meio de hidrólise enzimática produzida pela atividade da microbiota do solo e de outros processos de degradação do material orgânico (Silva et al., 2011). A mineralização dos constituintes nitrogenados libera, para a solução do solo, íons inorgânicos de nitrogênio, principalmente, amônio e nitrato (Santos et al., 2006). Os resultados apresentados diferem dos obtidos em estudo de Medeiros et al. (2005) ao se constatar que houve aumento da concentração de $\mathrm{N}$ ao longo do perfil de um solo irrigado com água residuária doméstica tratada.

Observou-se, na Figura 2A, que os valores de CEes diminuíram ao longo do perfil do solo, para todos os tratamentos aplicados. Na profundidade de 0,0 a $0,20 \mathrm{~m}$ os maiores valores foram apresentados para todos os tratamentos, sendo o tratamento $\mathrm{T} 1$ o que apresentou menores valores com relação aos demais tratamentos e o tratamento $\mathrm{T} 5$ apresentou maiores valores, nas duas profundidades estudadas.

Constatou-se, ainda, que ocorreu um aumento no valor da CEes do solo, para as duas profundidades estudadas, à medida que se aplicam maiores doses de percolado de aterro sanitário, o que implica na possibilidade de acúmulo de íons no perfil do solo já que o valor médio da condutividade elétrica do percolado foi de 16,40 dS m${ }^{-1}$ (Tabela 3). Esses resultados corroboram com Silva et al. (2011), ao proceder estudos com aplicação de percolado de resíduo sólido urbano em Cambissolo cultivado com capim Tifton 85.

Evidenciou-se, na Figura 2B, que ocorreu alteração nos valores de $\mathrm{K}^{+}$, ao longo do perfil do solo, para todos os tratamentos, com exceção do tratamento T1. Os tratamentos $\mathrm{T} 2, \mathrm{~T} 3, \mathrm{~T} 4 \mathrm{e}$ T5, apresentaram comportamentos semelhantes, encontrando-se, na profundidade de 0,0 a $0,20 \mathrm{~m}$, os maiores valores de $\mathrm{K}^{+}$. Em condições experimentais diferentes, Erthal et al. (2010) relataram que a concentração de $\mathrm{K}^{+}$aumentou 

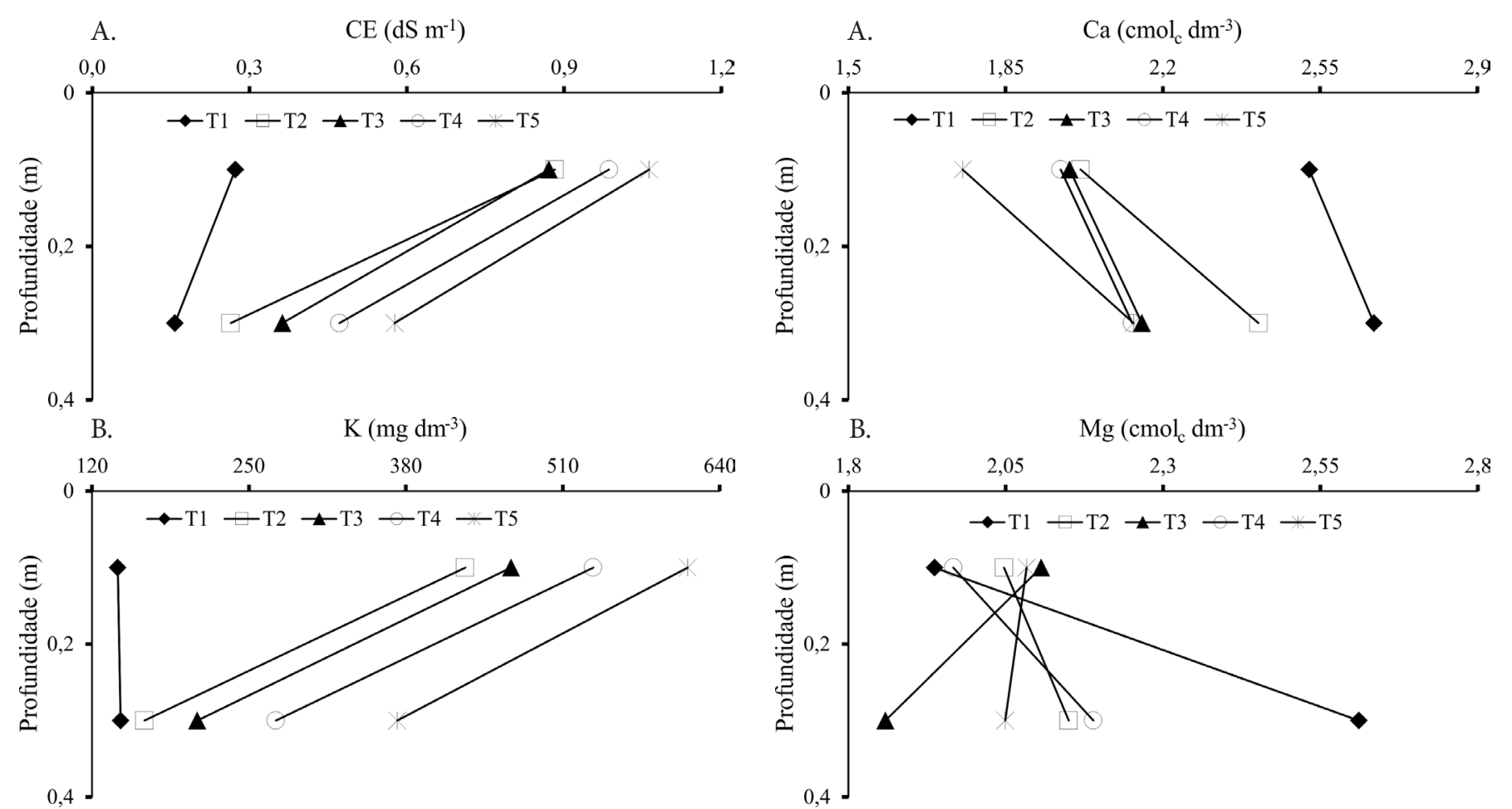

Figura 2. Alterações dos valores de CEes $\left(\mathrm{dS} \mathrm{m}^{-1}\right)$ e $\mathrm{K}(\mathrm{mg}$ $\mathrm{dm}^{-3}$ ) em função da profundidade do solo e das doses de percolado de aterro sanitário + água de abastecimento conforme Tabela 4

consideravelmente nos primeiros $0,10 \mathrm{~m}$ de profundidade do solo, com todas as taxas de aplicação da água residuária de bovinocultura, ao longo do período experimental.

Destaca-se, também, o fato de que, à medida que se aumentaram as doses de percolado de aterro sanitário aplicadas no solo, do tratamento T2 para o T5, ocorreu um aumento maior nas concentrações de $\mathrm{K}^{+}$com relação ao tratamento anterior para as duas profundidades, o que pode ser justificado pelas altas concentrações de $\mathrm{K}^{+}$no percolado de aterro sanitário (Tabela 3). De acordo com a classificação elaborada pela CFSEMG (1999), os teores de $\mathrm{K}^{+}$permitem classificar, agronomicamente, o solo estudado como muito bom, já que para todos os tratamentos analisados foram obtidos resultados superiores a $120 \mathrm{mg} \mathrm{dm}^{-3}$.

As concentrações de $\mathrm{Ca}^{2+}$ oscilaram apenas em relação à profundidade, como apresentado na Figura 3A. Notou-se que os valores de $\mathrm{Ca}^{2+}$ aumentaram ao longo do perfil do solo para todos os tratamentos aplicados, demonstrando que ocorreu lixiviação deste elemento. Os tratamentos T3 e T4 apresentaram comportamentos semelhantes, variando muito pouco de uma profundidade para outra. Comparando os tratamentos aplicados constatou-se que quanto maior a dose de percolado de aterro sanitário menor será a concentração de $\mathrm{Ca}^{2+}$ no solo.

Uma explicação para o aumento das concentrações $\mathrm{de} \mathrm{Ca}^{2+}$ ao longo do perfil do solo se deve à alta concentração deste nutriente no percolado de aterro sanitário (Tabela 3), além da formação geológica dos solos da região em que predominam as rochas calcárias. Para Medeiros et al. (2005) o aumento ou diminuição das concentrações de $\mathrm{Ca}^{2+}$ no solo está diretamente relacionado à concentração deste elemento na água residuária utilizada, à concentração absorvida pelas culturas e à lixiviação no perfil do solo.

Figura 3. Alterações dos valores de Ca $\left(\mathrm{cmol}_{\mathrm{c}} \mathrm{dm}^{-3}\right) \mathrm{e}$ $\mathrm{Mg}\left(\mathrm{cmol}_{\mathrm{c}} \mathrm{dm}^{-3}\right)$ em função da profundidade do solo e das doses de percolado de aterro sanitário + água de abastecimento conforme Tabela 4

De acordo com a CFSEMG (1999), a classificação agronômica de interpretação de fertilidade do solo para os valores de $\mathrm{Ca}^{2+}$ é caracterizada como média $\left(1,21\right.$ a $\left.2,40 \mathrm{cmol}_{\mathrm{c}} \mathrm{dm}^{-3}\right)$ para os tratamentos $\mathrm{T} 2, \mathrm{~T} 3, \mathrm{~T} 4 \mathrm{e} \mathrm{T} 5$ nas duas profundidades estudadas, e como boa $\left(2,41\right.$ a $\left.4,00 \mathrm{cmol}_{c} \mathrm{dm}^{-3}\right)$ para o tratamento $\mathrm{T} 1$ nas duas profundidades estudadas.

Na Figura 3B evidenciou-se que apenas a profundidade favoreceu diferenças nos valores de $\mathrm{Mg}^{2+}$, para todos os tratamentos aplicados. Os valores de $\mathrm{Mg}^{2+}$ apresentaram comportamentos distintos em relação aos tratamentos aplicados cujos tratamentos $\mathrm{T} 1$, T2 e T4, aumentaram suas concentrações ao longo do perfil do solo; diferentemente dos tratamentos T3 e T5, porém, na profundidade de 0,0 a $0,20 \mathrm{~m}$ as concentrações foram bastante próximas, destacando-se o tratamento T1 que, nesta profundidade, apresenta valor menor que os demais tratamentos.

Para a profundidade de 0,20 a $0,40 \mathrm{~m}$, os tratamentos T1 e T3 foram os que apresentaram maiores e menores concentrações de $\mathrm{Mg}^{2+}$, respectivamente. Observando todos os tratamentos aplicados, constatou-se que não houve uma relação entre as doses de percolado de aterro sanitário e a concentração do $\mathrm{Mg}^{2+}$, ao longo do perfil do solo, não se assemelhando a outros estudos, nos quais tenha ocorrido incremento nas concentrações, como relatado por Medeiros et al. (2005) e Silva et al. (2011).

A classificação agronômica de interpretação de fertilidade do solo atribuída pela CFSEMG (1999), para os valores de $\mathrm{Mg}^{2+}$ é caracterizada como muito boa ( $\left.>1,50 \mathrm{cmol}_{c} \mathrm{dm}^{-3}\right)$ para todos os tratamentos e profundidades estudadas.

$\mathrm{Na}$ Figura 4A verificou-se que apenas a profundidade favoreceu diferenças nos valores de SB, para todos os tratamentos aplicados. Os valores da SB diminuíram 

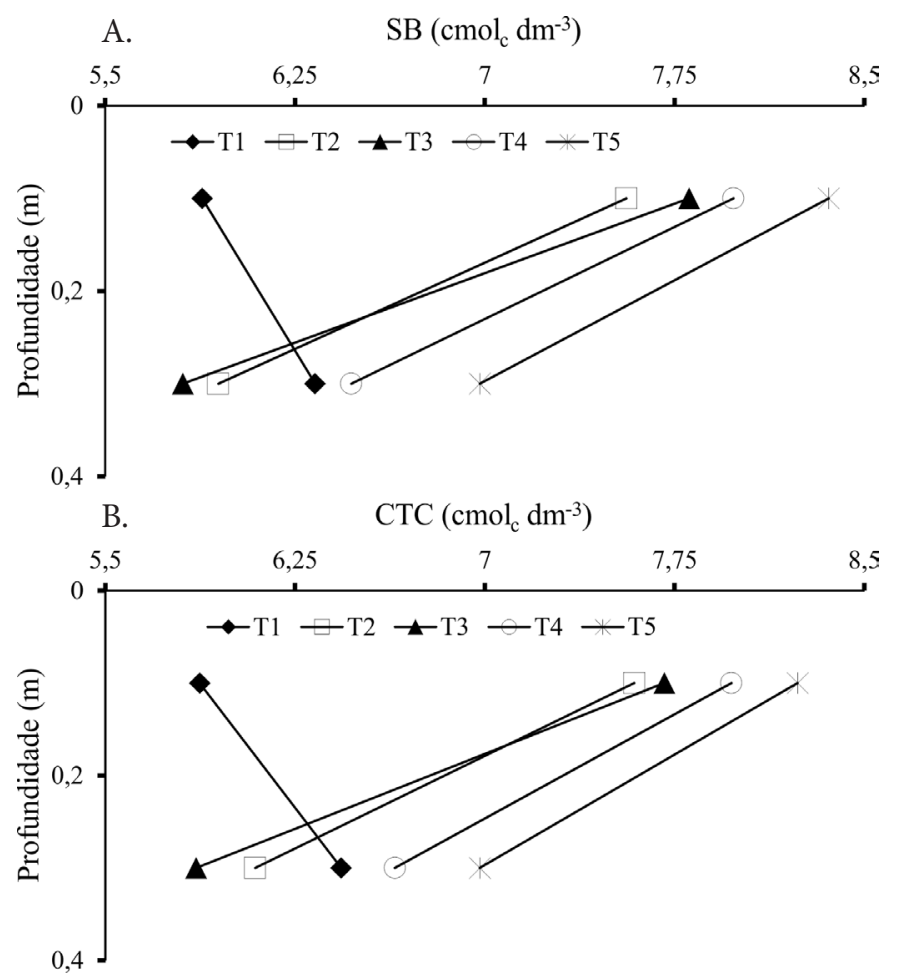

Figura 4. Alterações dos valores de soma das bases - SB $\left(\mathrm{cmol}_{\mathrm{c}} \mathrm{dm}^{-3}\right)$ e capacidade de troca catiônica - CTC $\left(\mathrm{cmol}_{\mathrm{c}}\right.$ $\mathrm{dm}^{-3}$ ) em função da profundidade do solo e das doses de percolado de aterro sanitário + água de abastecimento conforme Tabela 4

consideravelmente, ao longo do perfil do solo, para todos os tratamentos aplicados, com exceção do tratamento T1, que, diferentemente dos demais, apresentou um aumento considerável na concentração de SB. No trabalho desenvolvido por Erthal et al. (2010) com água residuária de bovinocultura em condições experimentais diferentes das encontradas no presente trabalho, notou-se aumento dos valores de SB com os incrementos nas taxas de aplicação do efluente.

Os tratamentos T2 a T5 apresentaram comportamentos semelhantes em que na profundidade de 0,0 a $0,20 \mathrm{~m}$ se encontram os maiores valores de concentração de SB. Destaca-se também, o fato de que, à medida que se aumentaram as doses de percolado de aterro sanitário aplicadas no solo, do tratamento T2 para o T5, ocorreu um aumento maior nos valores da SB nas duas profundidades estudadas, o que pode ser justificado devido às altas concentrações de nutrientes no percolado de aterro sanitário, sofrendo influência principalmente do $\mathrm{K}^{+}$.

No tratamento T1 houve lixiviação de nutrientes justificando o aumento de SB na camada 0,20 a $0,40 \mathrm{~m}$ quando comparada com a camada de 0,0 a $0,20 \mathrm{~m}$.

De acordo com a classificação elaborada pela CFSEMG (1999), os valores da SB permitem classificar agronomicamente o solo estudado como bom $\left(3,61\right.$ a $\left.6,00 \mathrm{cmol}_{c} \mathrm{dm}^{-3}\right)$ para o tratamento $\mathrm{T} 1 \mathrm{n}$ n profundidade de 0,0 a $0,20 \mathrm{~m}$ e para os tratamentos T2 e T3 na profundidade de 0,20 a $0,40 \mathrm{~m}$ e classificação de muito bom $\left(>6,00 \mathrm{cmol}_{c} \mathrm{dm}^{-3}\right)$, para o tratamento T1 na profundidade de 0,20 a $0,40 \mathrm{~m}$ e para os tratamentos T2 e T3 na profundidade de 0,0 a $0,20 \mathrm{~m}$ e T4 e T5 nas duas profundidades estudadas.

Apenas a profundidade favoreceu diferenças nos valores da CTC, para todos os tratamentos (Figura 4B). Da mesma forma que no comportamento da SB, quando se observou que os valores da CTC diminuíram, ao longo do perfil do solo, para todos os tratamentos aplicados, com exceção do tratamento T1 que, diferentemente dos demais, apresentou um aumento considerável na concentração da CTC.

Em condições experimentais diferentes, Erthal et al. (2010) constataram aumento da CTC com acréscimos das taxas de aplicação de água residuária da bovinocultura, principalmente nas camadas superficiais do solo. No trabalho apresentado por Dal Bosco et al. (2010) evidenciou-se baixa concentração de matéria orgânica na água residuária de suinocultura utilizada no estudo o que, provavelmente, acarretou a lixiviação dos íons presentes no solo para as camadas mais profundas resultando em maior CTC para as profundidades de 0,20 a $0,40 \mathrm{~m}$ e de 0,40 a $0,60 \mathrm{~m}$.

Os tratamentos T2, T3, T4 e T5 apresentaram comportamentos semelhantes, em que foram encontrados, na profundidade de 0,0 a 0,20 , os maiores valores das concentrações da CTC. Destaca-se também o fato de que sempre que se aumentaram as doses de percolado de aterro sanitário aplicadas no solo, do tratamento T2 para o T5, ocorreu um aumento maior nos valores da CTC nas duas profundidades estudadas, o que pode ser justificado em virtude das altas concentrações de nutrientes no percolado de aterro sanitário (Tabela 3). Segundo Erthal et al. (2010), os aumentos na SB e CTC com a aplicação de águas residuárias são atribuídos à alta concentração de íons e aos coloides orgânicos presentes nos efluentes.

Já que todos os valores de CTC se encontram entre 4,31 a $8,60 \mathrm{cmol}_{c} \mathrm{dm}^{-3}$ o solo é classificado agronomicamente como médio.

\section{Conclusões}

1. As características químicas analisadas variaram apenas com relação às profundidades, em que a condutividade elétrica do extrato de saturação do solo, a matéria orgânica, o nitrogênio, o potássio, a soma de bases e a capacidade de troca catiônica diminuíram ao longo do perfil do solo enquanto o cálcio aumentou e o magnésio se manteve constante.

2. O tratamento correspondente a $1 \mathrm{~mm}$ de PAST $+\mathrm{AA}$ foi o mais recomendado para aplicação em argissolo cultivado com capim elefante.

3. Elevadas dosagens do percolado de aterro sanitário aplicadas no argissolo favorecem redução na sua qualidade.

4. A recirculação do percolado nas células do aterro sanitário, aliada à produção de capim elefante, favorece tanto uma destinação final e tratamento viável para esse resíduo líquido, quanto à produção de briquetes para fins energéticos a partir de biomassa vegetal desta cultura para substituição da madeira, em fábricas de material cerâmico e padarias do semiárido.

\section{Agradecimentos}

Ao $\mathrm{CNPq}$, pelo apoio financeiro, e à CAPES, pela Bolsa de Mestrado. 


\section{Literatura Citada}

Allen, R. G.; Pereira, L. S.; Raes, D.; Smith, M. Evapotranspiracíon del cultivo, Guías para la determinación de los requerimientos de agua de los cultivos. Roma: FAO, 2006. 298p.

Bortolin, J. R. M.; Malagutti Filho, W. Método da eletrorresistividade aplicado no monitoramento temporal da pluma de contaminação em área de disposição de resíduos sólidos urbanos. Engenharia Sanitária e Ambiental, v.15, p.367-374, 2010. http://dx.doi. org/10.1590/S1413-41522010000400009

Carmo Filho, F.; Oliveira, O. F. Mossoró: Um município do semi-árido nordestino, caracterização climática e aspecto florístico. Mossoró: ESAM, 1995. 62p. (Coleção Mossoroense, série B).

Castilhos Júnior, A. B.; Dalsasso, R. L.; Rohers, F. Pré-tratamento de lixiviados de aterros sanitários por filtração direta ascendente e coluna de carvão ativado. Engenharia Sanitária e Ambiental, v.15, p.385-392, 2010. http://dx.doi.org/10.1590/S1413-41522010000400011

CFSEMG - Comissão de Fertilidade do Solo do Estado de Minas Gerais -. Recomendações para o uso de corretivos e fertilizantes em Minas Gerais - 5a aproximação. Viçosa: 1999. 359p.

Corrêa, C. R. S.; Abrahão, C. E. C.; Carpintero, M. C. C.; Anaruma Filho, F. $\mathrm{O}$ aterro sanitário como fator de risco para doenças respiratórias em crianças. Jornal de Pediatria, v.87, p.319-324, 2011.

Dacanal, M.; Beal, L. L. Filtro anaeróbio associado à membrana de microfiltração tratando lixiviado de aterro sanitário. Engenharia Sanitária e Ambiental, v.15, p.11-18, 2010. http://dx.doi. org/10.1590/S1413-41522010000100002

Dal Bosco, T. C.; Sampaio, S. C.; Opazo, M. A. U.; Gomes, S. D.; Nóbrega, L. H. P. Aplicação de água residuária de suinocultura em solo cultivado com soja: Cobre e zinco no material escoado e no solo. Engenharia Agrícola, v.28, p.699-709, 2008. http://dx.doi. org/10.1590/S0100-69162008000400010

Donagema, G. K.; Campos, D. V. B.; Calderano, S. B.; Teixeira, W. G.; Viana, J. H. M. Manual de métodos de análise de solos. Rio de Janeiro: Embrapa Solos, 2011. 230p.

EMBRAPA - Empresa Brasileira de Pesquisa Agropecuária. Sistema Brasileiro de Classificação de Solos. 3.ed. Brasília: Embrapa Solos, 2013.353p.

Erthal, V. J. T.; Ferreira, P. A.; Matos, A. T.; Pereira, O. G. Alterações físicas e químicas de um Argissolo pela aplicação de água residuária de bovinocultura. Revista Brasileira de Engenharia Agrícola e Ambiental, v.14, p.467-477, 2010. http://dx.doi. org/10.1590/S1415-43662010000500003

Ferreira, D. F. Sisvar: A computer statistical analysis system. Ciência e Agrotecnologia, v.35, p.1039-1042, 2011. http://dx.doi. org/10.1590/S1413-70542011000600001

França, R. G.; Ruaro, E. C. R. Diagnóstico da disposição final dos resíduos sólidos urbanos na região da Associação dos Municípios do Alto Irani (AMAI), Santa Catarina. Ciência \& Saúde Coletiva, v.14, p.2191-2197, 2009. http://dx.doi.org/10.1590/S1413-81232009000600026

Lopes, R. S.; Fonseca, D. M.; Oliveira, R. A.; Nascimento Júnior, D.; Andrade, A. C.; Stock, L. A.; Martins, C. E. Disponibilidade de matéria seca em pastagens de capim-elefante irrigadas. Ciência e Agrotecnologia, v.27, p.1388-1394, 2003. http://dx.doi. org/10.1590/S1413-70542003000600025

Martins, C. L.; Castilhos Júnior, A. B.; Costa, R. H. R. Desempenho de sistema de tratamento de lixiviado de aterro sanitário com recirculação do efluente. Engenharia Sanitária e Ambiental, v.15, p.401-410, 2010. http://dx.doi.org/10.1590/S1413-41522010000400013
Matos, A. T.; Carvalho, A. L.; Azevedo, I. C. D. d'A. Viabilidade do aproveitamento agrícola de percolados de resíduos sólidos urbanos. Revista Brasileira de Engenharia Agrícola e Ambiental, v.12, p.435440, 2008. http://dx.doi.org/10.1590/S1415-43662008000400015

Matos, A. T.; Silva, D. F.; Lo Monaco, P. A. V.; Pereira, O. G. Produtividade e composição química do capim-Tifton 85 submetido a diferentes taxas de aplicação do percolado de resíduo sólido urbano. Engenharia Agrícola, v.33, p.188-200, 2013. http:// dx.doi.org/10.1590/S0100-69162013000100019

Medeiros, S. S.; Soares, A. A.; Ferreira, P. A.; Matos, A. T.; Souza, J. A. A. Utilização de água residuária de origem doméstica na agricultura: Estudo das alterações químicas do solo. Revista Brasileira de Engenharia Agrícola e Ambiental, v.9, p.603-612, 2005. http://dx.doi.org/10.1590/S1415-43662005000400026

Moreira, C. A.; Braga, A. C. O. Anomalias de cargabilidade em aterro de resíduos sólidos domiciliares. Revista Brasileira de Geofísica, v. 27, p. 55-62. 2009. http://dx.doi.org/10.1590/S0102261X2009000100005

Oliveira, M. T.; Moreira, C. A.; Menezes, A. M. C. Aplicação do método de polarização induzida em área de disposição de resíduos sólidos no município de Caçapava do Sul - RS. Revista Brasileira de Geofísica, v.29, p.377-384. 2011. http://dx.doi.org/10.1590/ S0102-261X2011000200012

Rice, E. W.; Baird, R. B.; Clesceri, A. D. Standard methods for the examination of water and wastewater. 22. ed. Washington: APHA, AWWA, WPCR, 2012. 1496p.

Santos, H. C.; Oliveira, F. H. T.; Arruda, J. A.; Lopes, A. R. S.; Souza Júnior, R. F.; Farias, D. R. Amostragem para avaliação da fertilidade do solo em função da variabilidade de suas características químicas. Revista Brasileira de Engenharia Agrícola e Ambiental, v.13, p.849854, 2009. http://dx.doi.org/10.1590/S1415-43662009000700006

Santos, S. S.; Soares A. A.; Matos, A. T.; Mantovani, E. C.; Batista, R. O. Efeitos da aplicação localizada de esgoto sanitário tratado nas características químicas do solo. Engenharia na Agricultura, v.14, p.32-38, 2006.

Silva, D. F.; Matos, A. T.; Pereira, O. G.; Cecon, P. R.; Batista, R. O.; Moreira, D. A. Alteração química de solo cultivado com capim Tifton 85 (Cynodon spp.) e fertirrigado com percolado de resíduo sólido urbano. Acta Scientiarum. Technology. v.33, p.243-251, 2011. http://dx.doi.org/10.4025/actascitechnol.v33i3.6124

Silva, D. F.; Matos, A. T.; Pereira, O. G.; Cecon, P. R.; Moreira, D. A. Disponibilidade de sódio em solo com capim tifton e aplicação de percolado de resíduo sólido. Revista Brasileira de Engenharia Agrícola e Ambiental, v.14, p.1094-1100, 2010. http://dx.doi. org/10.1590/S1415-43662010001000011

Silva, T. N.; Campos, L. M. S. Avaliação da produção e qualidade do gás de aterro para energia no aterro sanitário dos Bandeirantes SP. Engenharia Sanitária e Ambiental, v.13, p.88-96, 2008. http:// dx.doi.org/10.1590/S1413-41522008000100012

Smanhotto, A.; Sousa, A. P.; Sampaio, S. C.; Nóbrega, L. H. P.; Prior, M. Cobre e zinco no material percolado e no solo com a aplicação de água residuária de suinocultura em solo cultivado com soja. Engenharia Agrícola, v.30, p.346-357, 2010. http://dx.doi. org/10.1590/S0100-69162010000200017

Queiroz, L. M.; Amaral, M. S.; Morita, D. M.; Yabroudi, S. C.; Alem Sobrinho, P. Aplicação de processos físico-químicos como alternativa de pré e pós-tratamento de lixiviados de aterros sanitários. Engenharia Sanitária e Ambiental, v.16, p.403-410, 2011. http://dx.doi.org/10.1590/S1413-41522011000400012 